\title{
DYNAMIC POSTUROGRAPHY FINDINGS IN WORKERS EXPOSED TO TOLUENE
}

\author{
By \\ Hosni NA, ${ }^{*}$ Hassan MA, ${ }^{* *}$ Samir AM,* \\ El-Dessouky TM, ${ }^{*}$ El-mezayen $\mathrm{HA}^{* * * *}$ \\ * Audiology Unit, ENT Department, Faculty of Medicine, Cairo University, Egypt. \\ **Industrial Medicine and Occupational Diseases Department, \\ Faculty of Medicine, Cairo University, Egypt. \\ ***Biochemistry Department, Faculty of science, Helwan University, Egypt.
}

\begin{abstract}
:
Background Exposure to volatile organic solvents as toluene, in the workplace, is associated with deleterious effects involved in postural regulation. Objectives: The aim of this study is to detect the disturbances of the vestibular system due to exposure to toluene using dynamic posturography, putting a hypothesis to use dynamic posturography as a possible tool to identify the effects on balance among workers exposed to toluene. Subjects and methods: the study was performed on 30 workers exposed to toluene and 30 workers non exposed (control). History, dynamic posturography (the central integration of the vestibular, visual, and somatosensory inflow is evaluated using sensoriorganization test (SOT)) and hippuric acid measurement in urine were performed to both groups. Results: hippuric acid levels in urine were statistically significant higher among exposed workers when compared to the control. Dynamic posturography results were statistically significant lower in the exposed group in conditions SOT $3(p=0.015)$, SOT $4(p=0.014)$, SOT $5,(p=0.001)$ SOT $6(p=0.000)$ and $\mathrm{CS}(\mathrm{P}=0.000)$ when compared to control group. A statistically significant negative correlation between urinary hippuric acid and dynamic posturography. There were significant negative correlation between duration of exposure to toluene and dynamic posturography. Conclusion: Exposure to toluene affects vestibular system so dynamic posturography is useful in balance assessment in workers exposed to toluene.
\end{abstract}

Key words: Dynamic posturography - Hippuric acid- Postural regulation- Toluene 


\section{Introduction:}

Solvents are lipophilic and have a high affinity for lipid-rich tissues such as the brain tissue. They are known to be neurotoxic substances, causing damage to the brainstem, cerebellum, and cerebral cortex (Gopal, 2008). Solvents induced toxicity, resulting from long term exposure has been studied (Iwata et al 2005; Herpin et al.2008; Murata et al 2010). However, in the field of occupational health, using dynamic Posturography to determine its effects on balance has not yet clearly investigated. Computerized dynamic posturography (CDP) testing is a technique used to assess underlying sensory and motor control impairments associated with balance disorders (Aylott and Prasher 2002). Vestibular system integrity is important in balance control (Nickelsson et al 1997 ; Allum and Shepard 1999). Both animal experiments and human studies point that solvents exposure lead to vestibular disturbances (Iwata et al 2005; Herpin et al.2008; Murata et al 2010). Solvents used in industry are known to affect balance are toluene, styrene, carbon disulfide, trichloroethylene and xylene (Axelsson and Hogstedt 1994). The neurotoxic effects of such chemicals on exposed workers can be acute in the form of narcosis, central nervous system
(CNS) depression, respiratory arrest, unconsciousness and even death. In addition, feelings of unsteadiness and vertigo (Axelsson and Hogstedt 1994). The evidence for chronic effects points to peripheral neuropathy and mild toxic encephalopathy in solvent-exposed workers ( Nickelsson et al 1997). Some authors found that investigation of the vestibular system may be a valuable complement to the traditional clinical investigation used in the diagnosis of chronic toxic encephalopathy among workers exposed to chronic solvents as toluene (Axelsson and Hogstedt 1994; Allum and Shepard 1999; Aylott and Prasher 2002). Others found abnormalities in dynamic posturography in workers exposed to industrial solvents as toluene (Nickelsson et al 1997; Herpin et al 2009). So the aim of this study is to detect the disturbances of the vestibular system in workers exposed to toluene using dynamic posturography, putting a hypothesis to use dynamic posturography as a possible tool to identify the effects on balance among workers chronically exposed to toluene

\section{Subjects and methods:}

\section{Subjects:}

The exposed group consists of 30 male workers engaged in textile factory in Giza government in Egypt, all of them working 
in dying and printing sectors, exposed to toluene. They were selected following a questionnaire survey and otolaryngological examinations. Inclusion criteria: eight hours exposure to toluene, for six days per week. Exclusion criteria: those with middle ear pathology, past ear surgery, head injuries, ototoxic drug treatment, diabetes, hypertension, neurologic diseases and alcohol abuse were excluded from the study. The control group consisted of 30 non-exposed workers, employed in other sectors in the same factory, matching the exposed group as regards age, gender, socioeconomic status and special habits of medical importance. Prior to this study, approval from the factory chairman was obtained. A consent and an approval to gave samples and to perform dynamic Posturography tests was obtained from each subject, who was going to share in the study, after explaining to them the aim and importance of the study. Strict confidentiality was observed throughout sample collection, coding, testing and recording of the results. Subjects were allowed to obtain copies of the results.

\section{Methods:}

The study was conducted from March to June 2010. The workers were referred to audiology unit in Kasr El Aini hospital, Cairo University, outpatient clinic. The study population were subjected to designed questionnaire include medical , personal , occupational history (to identify the agents, duration of exposure and symptoms as, dizziness, vertigo, nausea, fatigue, mood changes and poor concentration). Prior to posturography testing, an otoscopic examination of the ears was done to rule out any pathological ear conditions. Assessment of occupational exposure to toluene was performed by measuring urinary Hippuric acid in urine at the end of the shift.

Hippuic acid measurement: Chemicals and reagents: Hippuric acid, benzenesulfonyl chloride (BSC), acetic acid and methanol (HPLC grade) (Sigma), and pyridine (guaranteed reagent), Ultra-pure water. Sample preparation: Urine sample (Control \& exposed).-Standard samples were prepared by adding hippuric acid to ultra-pure water, and the final concentration was adjusted to $0.125,0.25,0.5,1.0,1.5$ and $2.0 \mathrm{mg} / \mathrm{ml}$. Determination of hippuric acid urine sample $0.2 \mathrm{ml}$ was mixed with $0.25 \mathrm{ml}$ pyridine, and subsequently with $0.1 \mathrm{ml}$ BSC. Then, 0.125, 0.25, 0.5 1.0 or $1.5 \mathrm{ml}$ ultra-pure water was added. The spectra from 300 to $700 \mathrm{~nm}$ of the mixtures were recorded using a spectrophotometer (Biosystem, BTS 302, Spain). A color chart for semiquantitation of hippuric acid was 
prepared using standard samples containing $0.125,0.25,0.5,1.0,1.5$ or $2.0 \mathrm{mg} / \mathrm{ml}$ hippuric acid. Then, the concentrations in all samples from the healthy volunteers and exposed workers samples were obtained by comparing reddish-color depth of the mixtures with the color chart, subjectively using the naked eye. When color of the sample mixture was intermediate between the colors of two successive standard mixtures, the concentration of hippuric acid was determined to be an intermediate value of the concentrations in the two standard samples (Yoshida et al., 2005).

Detection of the influence of toluene on the vestibular system was done using computerized dynamic posturography NEUROCOM SMART Equi Test Balance Master calibrated according to ISO standards. The sensoriorganization test (SOT) was performed. In the sensory organization tests the central integration of the vestibular, visual, and somatosensory inflow is evaluated. The study was conducted in audiology unit Kasr El Aini hospital, Cairo University, outpatient clinic. It included 6 conditions SOT 1 , eyes open, fixed surface and visual surrounds; SOT 2, eyes closed, fixed surface; SOT 3, eyes open fixed surface, sway referenced visual surround; SOT 4, eyes open, sway referenced surface, fixed visual surround; SOT 5, eyes closed, sway referenced surface; SOT 6, eyes open, sway referenced surface and visual surround. The equilibrium composite score (CS) quantifies the postural stability under each trial for all conditions. It is the weighted average of scores on all sway conditions and characterizes an individual's overall level of performance. Each condition consisted of three 10 seconds trials. The study population was properly instructed, fitted with safety harness, subjects stand on a platform enclosed by a visual surrounding, properly aligned on the force plate and instructed prior to testing (Black, 2001).

\section{Statistical analysis:}

Data obtained from the study was coded and entered using the statistical package SPSS version 16 (SPSS inc. Chicago, IL, USA). The mean values, standard deviation (SD), minimum, maximum and ranges were then estimated for quantitative variables, as for the qualitative variables, the frequency distribution was calculated. Comparisons between exposed and control groups were done using the independent simple t-test. The Correlations between individual variables were calculated using Pearson's correlation coefficient. P-values less than 0.05 and less than 0.001 were considered statistically significant and highly significant, respectively. 


\section{Results:}

The study population consists of exposed and control group. The exposed group consisted of 30 workers exposed to toluene, their mean age was $(39.97 \pm 8.58)$, ranging from (23-54) years. Showing no statistically significant difference $(\mathrm{p}=$ 0.941) when compared to control group. The control group consists of 30 workers whose mean age was $(39.80 \pm 8.83)$ years, ranging from (24 - 52) years. The duration of exposure to toluene was $(15.10 \pm 9.54)$ years, ranging from (5 - 37) years among exposed group. Frequency distribution of some clinical manifestations due to long term exposure to toluene among the studied groups was shown in table (1). Dynamic Posturography findings among studied groups were summarized in table (2). Table (3) shows that the mean value of dynamic postourgraphy findings in conditions, SOT 6 and CS were highly statistically significantly lower $(p<0.001)$ when compared to the control group. The mean value of dynamic postourgraphy findings in conditions SOT 3, SOT 4, SOT 5 were statistically significantly lower $(\mathrm{P}=0.015$, $\mathrm{P}=0.014, \mathrm{P}=0.001$ respectively ) when compared to the control group. Hippuric acid levels among exposed group were highly statistically significantly increased $(\mathrm{P}=0.000)$ table (3) when compared to the control group. Pearson Correlation analysis was performed between the level of urinary hippuric acid and dynamic posturography findings. There were statistically significant negative correlation between urinary hippuric acid and dynamic posturography findings in conditions, SOT $4(\mathrm{R}=-0.521, \mathrm{p}=0.003)$, SOT 5, $(\mathrm{R}=-0.433$, $\mathrm{p}=0.017)$, SOT $6(\mathrm{R}=-0.430, \mathrm{p}=0.015)$ and CS $(\mathrm{R}=-0.532, \mathrm{P}=0.003)$ among exposed group (table, 4$)$.

A statistically significant negative correlation between the duration of exposure to toluene, and dynamic posturography findings in conditions SOT $3(\mathrm{R}=-0.429, \mathrm{p}=0.018)$, SOT $4(\mathrm{R}=-0.389$, $\mathrm{p}=0.034)$, SOT 5, $(\mathrm{R}=-0.554, \mathrm{p}=0.001)$, SOT $6(R=-0.557, p=0.001)$ and $C S(R=-$ $0.637, \mathrm{P}=0.000$ ) among exposed group (table 5). 
Table (1): Frequency distribution of some clinical manifestations due to toluene exposure among studied groups.

\begin{tabular}{|l|c|c|c|c|c|}
\hline & \multicolumn{2}{|c|}{ Exposed } & \multicolumn{2}{c|}{ Control } & \multirow{2}{*}{ Po=30 } \\
& No & $\%$ & No & $\%$ & \\
\hline dizziness & 16 & 53 & 3 & 10 & $0.000^{* *}$ \\
\hline Vertigo & 5 & 17 & 0 & 0 & $0.02^{*}$ \\
\hline Nausea & 9 & 6 & 1 & 3 & $0.01^{*}$ \\
\hline Fatigue & 21 & 70 & 3 & 10 & $0.000^{* *}$ \\
\hline Mood changes & 19 & 63 & 1 & 3 & $0.000^{* *}$ \\
\hline Poor concentration & 14 & 46 & 1 & 3 & $0.000^{* *}$ \\
\hline Memory loss & 17 & 57 & 4 & 13 & $0.000^{* *}$ \\
\hline
\end{tabular}

$\mathrm{P}<0.05 *$ and $\mathrm{p}<0.001 * *$ were considered statistically significant and highly significant, respectively. 
Table (2): Dynamic posturography findings among studied groups

\begin{tabular}{|c|c|c|c|c|c|c|}
\hline & \multicolumn{3}{|c|}{$\begin{array}{c}\text { Exposed } \\
\text { no=30 }\end{array}$} & \multicolumn{3}{|c|}{$\begin{array}{l}\text { Control } \\
\text { no }=30\end{array}$} \\
\hline & $\max$ & Min & median & $\max$ & Min & Median \\
\hline SOT 1 & 85.66 & 96.00 & 94.42 & 90.66 & 96.0 & 95.00 \\
\hline SOT 2 & 95.60 & 79.00 & 91.58 & 88.00 & 96.00 & 91.25 \\
\hline SOT 3 & 96.00 & 70.66 & 91.00 & 84.33 & 95.33 & 92.25 \\
\hline SOT 4 & 91.33 & 59.33 & 82.45 & 70.33 & 95.00 & 87.00 \\
\hline SOT 5 & 78.33 & 35.00 & 63.66 & 84.00 & 58.00 & 69.17 \\
\hline SOT6 & 84.66 & 16.33 & 57.15 & 35.00 & 84.66 & 70.33 \\
\hline $\mathrm{CS}$ & 88.00 & 54.00 & 76.00 & 71.00 & 88.00 & 80.50 \\
\hline
\end{tabular}

SOT 1: sensoriorganization test condition 1, SOT 2: sensoriorganization test condition 2, SOT 3: sensoriorganization test condition 3, SOT 4: sensoriorganization test condition 4, SOT 5: sensoriorganization test condition 5, SOT6: sensoriorganization test condition 6, CS: composite score. 
Table (3): Mean \pm SD of dynamic Posturography findings and hippuric acid among exposed and control groups.

\begin{tabular}{|c|c|c|c|c|c|}
\hline & \multicolumn{2}{|c|}{ Exposed } & \multicolumn{2}{c|}{ Control } & P value \\
& Mean & SD & Mean & SD & \\
\hline SOT 1 & 93.25 & 2.53 & 94.34 & 1.63 & 0.054 \\
\hline SOT 2 & 90.99 & 4.30 & 91.92 & 2.33 & 0.302 \\
\hline SOT 3 & 88.74 & 6.88 & 92.18 & 2.92 & $0.015^{*}$ \\
\hline SOT 4 & 80.08 & 8.35 & 84.99 & 6.61 & $0.014^{*}$ \\
\hline SOT 5 & 60.89 & 11.04 & 69.67 & 7.32 & $0.001^{*}$ \\
\hline SOT 6 & 51.04 & 19.64 & 67.89 & 13.16 & $0.000^{* *}$ \\
\hline CS & 73.67 & 7.88 & 80.50 & 4.86 & $0.000^{* *}$ \\
\hline Hippuric acid in urine & 0.416 & 0.338 & 0.166 & 0.08 & $0.000^{* *}$ \\
\hline
\end{tabular}

$\mathrm{P}<0.05^{*}$ and $\mathrm{p}<0.001 * *$ were considered statistically significant and highly significant, respectively. SOT 1: sensoriorganization test condition 1, SOT 2: sensoriorganization test condition 2, SOT 3: sensoriorganization test condition 3, SOT 4: sensoriorganization test condition 4, SOT 5: sensoriorganization test condition 5, SOT6: sensoriorganization test condition 6,CS: composite score. Hippuric acid in urine $\mathrm{mg} / \mathrm{ml}$. 
Table (4): Pearson`s correlation between urinary hippuric acid and dynamic posturography findings among exposed group.

\begin{tabular}{|c|c|c|}
\hline & $\mathrm{R}$ & P value \\
\hline SOT 1 & -0.254 & 0.176 \\
\hline SOT 2 & -0.207 & 0.273 \\
\hline SOT 3 & -0.161 & 0.394 \\
\hline SOT4 & -0.521 & $0.003^{*}$ \\
\hline SOT5 & -0.433 & $0.017^{*}$ \\
\hline SOT 6 & -0.440 & $0.015^{*}$ \\
\hline CS & -0.523 & $0.003^{*}$ \\
\hline
\end{tabular}

$\mathrm{P}<0.05 *$ and $\mathrm{p}<0.001 * *$ were considered statistically significant and highly significant, respectively. SOT 1: sensoriorganization test condition 1, SOT 2: sensoriorganization test condition 2, SOT 3: sensoriorganization test condition 3, SOT 4: sensoriorganization test condition 4, SOT 5: sensoriorganization test condition 5, SOT6: sensoriorganization test condition 6, CS: composite score. 
Table (5): Pearson`s correlation between duration of exposure and dynamic posturography findings among exposed group.

\begin{tabular}{|c|c|c|}
\hline & $\mathrm{R}$ & P value \\
\hline SOT1 & -0.197 & 0.298 \\
\hline SOT2 & -0.292 & 0.118 \\
\hline SOT3 & -0.429 & $0.018^{*}$ \\
\hline SOT4 & -0.387 & $0.034^{*}$ \\
\hline SOT5 & -0.554 & $0.001^{*}$ \\
\hline SOT6 & -0.557 & $0.001^{*}$ \\
\hline CS & -0.637 & $0.000^{* *}$ \\
\hline
\end{tabular}

$\mathrm{P}<0.05^{*}$ and $\mathrm{p}<0.001 * *$ were considered statistically significant and highly significant, respectively. SOT 1: sensoriorganization test condition 1, SOT 2: sensoriorganization test condition 2, SOT 3: sensoriorganization test condition 3, SOT 4: sensoriorganization test condition 4, SOT 5: sensoriorganization test condition 5, SOT6: sensoriorganization test condition 6,CS: composite score. 


\section{Discussion:}

There is an increasing interest in studying the biological effect of organic solvents on balance, as they are widely spread in industry. Although organic solvents have been used in industry for about 150 years, serious concern for their vestibulotoxic effect began recently (Sułkowski et al., 2002). Organic solvents are highly volatile and lipid soluble, which increases their absorption in tissues and their binding to lipids. As the nervous tissue is mostly composed of lipids, so, it is particularly sensitive to solvent toxicity (Gopal 2008). In the current study exposure to toluene is investigated among workers in the textile manufacturing, in the printing sector using toluene in addition to colors in the dyeing process. Our results showed statistically significant increase in the frequency of clinical symptoms due to toluene exposure. In our study symptoms of toluene exposure were: dizziness $16(53 \%)$, fatigue 21 (70\%), mood changes 19 (63\%), memory loss 17 (57\%), poor concentration $14(46 \%)$, nausea $9(30 \%)$ and vertigo 5 $(17 \%)$. This is in concomitant with Crofton et al. 1994, who stated that dizziness is an early symptoms due to solvents exposure. Our results are in agreement with Lee et al. 2005, who reported that impaired memory, concentration levels and emotional disturbance were the complaints among shipyard painters workers occupationally exposed to toluene.

Solvents have higher volatility with generation of significant airborne concentrations of vapor. In this factory especially in sectors using toluene, there is relatively high temperature, lack of appropriate enclosure and exhaust ventilation systems of the work environment , these may all contribute to increase uptake of solvents by inhalation. Also the degree of physical exercise required by the work performed, increased the ventilatory volume per minute and thus the amount of solvent vapor absorbed increased. Also lack of wearing gloves and masks all the time of working contribute to increase risk of exposure to toluene in work place.

In accordance with our results, Orbaek and Nise 1989, examined the effects of toluene on 30 rotogravure printers, 33-61 years of age (mean 50), employed at two Swedish printing shops for 4-43 years (median 29). They reported statistically significant higher occurrences of fatigue $(60 \%)$, recent short-term memory problems (60\%), concentration difficulties $(40 \%)$, mood liability (27\%), and other neurasthenic symptoms. Moreover, Eller et al., 1999, who evaluated the chronic effects on the central nervous system due to exposure to 
low concentrations of toluene on workers in a rotogravure plant, ninety-eight male workers from a selection pool of 107 (92\%) were examined in addition to measuring of symptoms were obtained by answering questionnaires, they found (33\%) reporting concentration difficulties in highly exposed group (exposure to toluene for more than 12 years).

According to ACGIH , 2001, in humans, up to $75 \%$ of inhaled toluene is metabolized to hippuric acid (HA) and excreted in urine. Measuring hippuric acid in urine as internal dose of toluene exposure was studied (Kawai et al.,1996; Vrca et al., 1997; Fustinoni et al., 2009). In the current study there is statistically significant increase in hippuric acid in urine among exposed workers than their control $(\mathrm{P}=0.000)$. Our findings in concomitant with Mao et al. 2007, who found that mean urinary HA concentration was statistically significantly greater $(\mathrm{p}=0.043)$ among male spray painters exposed to toluene. Dynamic posturography provides quantitative assessment of both sensory and motor components of postural control along with how the sensory inputs to the brain interact and the integration of vestibular inputs with other sensory systems for postural control. Dynamic posturography is useful in diagnosis of vestibular disorders associated with impairment of the equilibrium (Luchikhin , 1997). So assessment of the effect of exposure to organic solvents on balance is an important problem for occupational medicine and audiology specialists. In this study we use dynamic posturography as a possible tool to identify the effects on balance in workers exposed to toluene. When comparing dynamic posturography results in both groups, we found dynamic posturography findings, statistically significantly lower in exposed group in conditions SOT $3(\mathrm{p}=0.015)$, SOT $4(\mathrm{p}=0.014)$, SOT $5,(\mathrm{p}=0.001)$ SOT $6(\mathrm{p}=0.000)$ and CS $(\mathrm{P}=0.000)$. These posturographic findings suggest vestibular abnormalities in solvents exposed workers. Our findings are in concomitant with Prasher et al., 2005, who found postural sway abnormalities in about a third of the aircraft maintenance workers exposed to mixture of solvents. Odkvist et al., 1992, reported that workers exposed to industrial solvents showed a significantly impaired equilibrium performance on the sensory organization test of dynamic posturography and he concluded that the disturbances could be within the posterior fossa structures. Also Nickelsson et al., 1997 examined sixty workers exposed to organic solvents . They were divided into four major groups: 7 repairmen, 11 house painters, 19 spray painters and 6 printer. These workers were 
investigated using videonystagmography (VNG) and dynamic posturography, they found reduced visual suppression ability, prolonged latency of saccades and pathology in the dynamic posturogaphy test results when they were compared with that of the control group. They indicated that the lesion is in the primary reflexes of the brain stem and cerebellum. These indications of the location of the lesion are supported by magnetic resonance imaging findings in patients with chronic toxic encephalopathy and autopsy results due to exposure to toluene. (Thoumas et al., 1996).

Numerous studies (Aylott and Prasher 2002; Yokoyama et al., 2002; Iwata et al., 2005) have indicated that vestibular disturbances are common in worker exposed to solvents. In rats, toluene is ototoxic, producing high frequency hearing loss and cochlear damage. This hearing loss is permanent, with damage to the outer hair cells of the cortical organ of the inner ear (Crofton et al., 1994). However the precise mechanisms underlying solvents affect balance control system are not studied in detail. Perhaps it is due to their direct assault upon the sensory cells of the vestibular neuroepithelia, followed by the effect of solvents on metabolic processes and enzymatic systems, which probably inhibit the protein synthesis (Aylott and
Prasher 2002). Smith et al. 1997 added that solvents have influence on the vestibular proprioceptive interaction.

Also our findings is in concomitant to Iwata et al., 2005 who clarified the neuromotor effects of long-term exposure to mixed organic solvents (toluene, styrene and n-hexane), postural sway and tremor were measured in 62 solvent workers of four Buddhist altar manufacturing factories who had worked for 1-46 (mean 12) year. Among the solvent workers, transversal and sagittal sways with eyes open and tremor were significantly related to toluene exposure $(\mathrm{p}<0.05)$.

Our findings showed statistically significant negative correlation between both hippuric acid level and posturography results in conditions, SOT $4(\mathrm{p}=0.003)$, SOT $5,(\mathrm{p}=0.017)$ SOT $6(\mathrm{p}=0.015)$ and $\mathrm{CS}(\mathrm{P}=0.003)$ and the duration of exposure to toluene and dynamic posturography findings in conditions SOT $3(\mathrm{p}=0.018)$, SOT $4(\mathrm{p}=0.034)$, SOT $5,(\mathrm{p}=0.001)$ SOT $6(\mathrm{p}=0.001)$ and $\mathrm{CS}(\mathrm{P}=0.000)$. This is in concomitant with Herpin et al., 2009 who evaluated 18 workers, mainly exposed to $n$-hexane and toluene in plant manufacturing adhesive materials, using posturography tests, balance control performance were lower in chronically exposed workers. They concluded that 
prolonged exposure to volatile organic solvents (chronic exposure), mainly $\mathrm{n}$-hexane and toluene, in the workplace is associated with deleterious central effects involved in postural regulation. Also Odkevist et al., 1992, found that during the early exposure to organic solvents no pathologic conditions will be found using dynamic posturography, later abnormalities appear in dynamic posturography and other otoneurologic tests . On the other hand Nickelsson et al., 1997, found no correlation between dynamic posturography results and duration of exposure to organic solvents. From the present study we can conclude that dynamic posturography is valuable in assessment of vestibular function, and can be used as clinical investigation of workers exposed to solvents. They can be used as preemployment and follow up assessment for worker exposed to toluene. However the size of the study sample was not large enough, so other studies with large sample size need to be conducted.

\section{Acknowledgment:}

The authors are grateful to all workers involved in this study for their cooperation. Also we want to thank audiology unit in Kasr El Aini hospital, Cairo University, outpatient clinic, for their help in performance of dynamic posturography tests.

\section{References:}

1. Allum, J.H. and Shepard, N.T. (1999). An overview of the clinical use of dynamic posturography in the differential diagnosis of balance disorders. J Vestib Res. 9(4):223-52.

2. American Conference of Governmental Industrial Hygienists (ACGIH) ( 2001). Documentation of the threshold limit values and biologic exposure indices, 7th ed American Conference of Governmental Industrial Hygienist, Cincinnati, $\mathrm{OH}$

3. Axelsson, O. and Hogstedt, C. (1994). The health effects of solvents. In: Zenz C, Dickerson OB, Horvath EP, editors. Occupational medicine, 3rd ed. St Louis (MI): Mosby-Year Book Inc, p.76-78.

4. Aylott, S. and Prasher, D. (2002). Solvents Impair Balance in Man. Noise and health 4(14): 63-71.

5. Black, F. (2001). What can posturography tell us about vestibular function?. Ann N Y Acad Sci 942:446-64.

6. Crofton, K.M. Lassiter, T.L. and Rebert, C.S. (1994). Solvent-induced ototoxicity in rats: an atypical selective mid-frequency hearing deficit. Hearing Res 80:23-30.

7. Eller, N. Netterstrøm,B. and Laursen, P. (1999). Risk of chronic effects on the central nervous system at low toluene exposure. Occup Med (Lond) 49 (6):389-95.

8. Fustinoni, S. Mercadante, R. and Campo, L. (2009). Self-collected urine sampling to study the kinetics of urinary toluene (and o-cresol) and define the best sampling time for biomonitoring. Int Arch Occup Environ Health 82(6):703-13.

9. Gopal, C. (2008) Audiological findings in individuals exposed to organic solvents: Case studies. Noise and Health. 10,74-82.

10. Herpin, G. Gauchard, G.C. Vouriot, A. Hannhart, B. Barot, A. Mur, J.M. Zmirou, N. D. and Perrin, P.P. (2008). Impaired neuromotor functions in hospital laboratory workers 
exposed to low levels of organic solvents. Neurotox Res. 13(3-4):185-96.

11. Herpin, G. Gargouri, I. Gauchard, G.C. Nisse, C. Khadhraoui, M. Elleuch, B. Zmirou, N. D. and Perrin, P.P. (2009). Effect of Chronic and Subchronic Organic Solvents Exposure on Balance Control of Workers in Plant Manufacturing Adhesive Materials. Neurotoxocology Research 15:179-186.

12. Iwata, T. Mori, H. Dakeishi, M. Onozaki, I. and Murata, K.(2005). Effects of mixed organic solvents neuromotor functions among workers in Buddhist altar manufacturing factories. J Occup Health. 47(2):143-8.

13. Kawai, T. Mizunuma, K. Okada, Y. Horiguchi, S. and Ikeda, M. (1996). Toluene itself as the best urinary marker of toluene exposure. Int Arch Occup Environ Health 68(5):289-97.

14. Lee, C.R. Jeong, K.S. Kim, Y. Yoo, C.I. Lee, J.H. and Choi, Y.H. (2005). Neurobehavioral changes of shipyard painters exposed to mixed organic solvents. Ind Health 43(2):320-6.

15. Luchikhin, L.A. (1997). Posturography: efficacy and prospects in Otorhinolaryngology. Vestn Otorinolaringol. (1):19-23.

16. Mao, I.F. Chang, F.K. and Chen, M.L. (2007). Delayed and competitively inhibited excretion of urinary hippuric acid in field workers coexposed to toluene, ethyl benzene, and xylene Arch Environ Contam Toxicol 53(4):678-83.

17. Murata, K. Inoue, O. Akutsu, M. and Iwata, T. (2010). Neuromotor effects of short-term and long-term exposures to trichloroethylene in workers. Am J Ind Med. 53(9):915-21.

18. Niklasson, M. Möller, C. Odkvist, L.M. Ekberg, K. Flodin, U. Dige, N. and Sköldestig, A. (1997). Are deficits in the equilibrium system relevant to the clinical investigation of solventinduced neurotoxicity?. Scand J Work Environ Health 23:206- 13.

19. Odkvist, L. Moller, C. and Thuomas, K. (1992). Otoneurologic disturbances caused by solvent pollution. Otoneurologic Head Neck Surg. 106(6):687-92.

20. Orbaek, P. and Nise, G. (1989). Neurasthenic complaints and psychometric function of toluene- exposed rotogravure printers. Am. J. Ind. Med 16:67-77.

21. Prasher, D. Al-Hajjaj, H. Aylott, S. and Aksentijevic, A. (2005). Effect of exposure to a mixture of solvents and noise on hearing and balance in aircraft maintenance workers. Noise Health 7(29):31-9.

22. Smith, L.B. Bhattacharya, A. Lemasters, G. Succop, P. Puhala, E. Medvedovic, M. and Joyce, J. (1997). Effect of Chronic low-level exposure to jet fuel on postural balance of US Air Force personnel. J Occup Environ Med 39:623-32.

23. Sułkowski, W. Kowalska, S. Matyja, W. Guzek, W. Wesolowski, W. Szymczak, W. and Kostrzewski, P. (2002). Effects of Occupational Exposure to a Mixture of Solvents on the Inner Ear: a Field Study. International Journal of Occupational Medicine and Environmental Health 15: 247-256.

24. Thoumas, K.A. Moller, C. Odkvist, L.M. et al. (1996). MRI in solvent induced chronic toxic encephalopathy. Acta Radio 37: 177-9.

25. Vrca, A. Bozicević, D. Bozikov, V. Fuchs, R. and Malinar, M. (1997). Brain stem evoked potentials and visual evoked potentials in relation to the length of occupational exposure to low levels of toluene. Acta Med Croatica 51(45):215-9.

26. Yokoyama, K. Araki, S. Nishikitani, M. and Sato, H. (2002). Computerized Posturography with Sway Frequency Analysis: Application in Occupational and Environmental Health Ind Health. 40(1):14-22.

27. Yoshida, M. Akane, A. Mitani, T. and Watabiki, T. (2005). Simple colorimetric semiquantitation method of hippuric acid in urine for demonstration of toluene abuse. Leg Med 7:198-200. 